\title{
Wnt signaling in liver disease: emerging trends from a bibliometric perspective
}

\author{
Guangyi Jiang ${ }^{1,2}$, Chiung-Kuei Huang ${ }^{3}$, Xinjie Zhang ${ }^{1,2}$, Xingyu $\mathbf{L v}^{1,2}$, Yifan Wang ${ }^{1,2}$, Tunan Yu ${ }^{1,2}$, Xiujun Cai ${ }^{\text {Corresp. }}$ \\ 1,2 \\ 1 Department of General Surgery, Sir Run Run Shaw Hospital, College of Medicine, Zhejiang University, Hangzhou, Zhejiang, China \\ 2 Key Laboratory of Laparoscopic Technology of Zhejiang Province, Sir Run Run Shaw Hospital, College of Medicine, Zhejiang University, Hangzhou, \\ Zhejiang, China \\ 3 \\ Liver Research Center, Rhode Island Hospital and The Warren Alpert Medical School of Brown University, Providence, RI, U.S. \\ Corresponding Author: Xiujun Cai \\ Email address: srrsh_cxj@zju.edu.cn
}

Background: The Wnt signaling pathway, an evolutionarily conserved molecular transduction cascade, has been identified to play a pivotal role in various physiological and pathological processes of the liver, including homeostasis, regeneration, cirrhosis, and hepatocellular carcinoma. In this study, we aimed to use a bibliometric method to evaluate the emerging trends on Wnt signaling in liver diseases.

Methods: Articles were retrieved from the Web of Science Core Collection (WoSCC). We used a bibliometric software, CiteSpace V 5.3.R4, to analyze the active countries or institutions in the research field, the landmark manuscripts, important subtopics, and evolution of scientific ideas.

Results: In total, 1,768 manuscripts were published, and each was cited 33.12 times on average. The U.S. published most of the manuscripts, and the most active center was the University of Pittsburgh. The top 5 landmark papers were identified by four bibliometric indexes including citation, burstness, centrality, and usage 2013 . The clustering process divided the whole area into 9 research subtopics, and the two major important subtopics were "liver zonation" and "hepatocellular carcinoma". Using the "Partof-Speech" technique, 1,743 terms representing scientific ideas were identified. After 2008, the bursting phrases were "liver development" , "progenitor cells," "hepatic stellate cells", "liver regeneration", "liver fibrosis", "epithelial-mesenchymal transition" and etc.

Conclusion: Using bibliometric methods, we quantitatively summarized the advancements and emerging trends in Wnt signaling in liver diseases. These bibliometric findings may pioneer the future direction of this field in the next few years, and further studies are needed. 
9 University, Hangzhou, Zhejiang, China.

\section{Author affiliations} Brown University, Providence, RI 02903, U.S.

\title{
Wnt signaling in liver disease: emerging trends from a bibliometric perspective
}

\author{
Guangyi Jianga,b Chiung-Kuei Huang ${ }^{\mathrm{c}}$; Xinjie Zhanga,b; Xingyu Lva,b; Yifan Wanga,b; Tunan \\ $\mathrm{Yu}^{\mathrm{a}, \mathrm{b}, *} ;$ Xiujun Caia,b,*
}

aDepartment of General Surgery, Sir Run Run Shaw Hospital, College of Medicine, Zhejiang bKey Laboratory of Laparoscopic Technology of Zhejiang Province, Sir Run Run Shaw Hospital, College of Medicine, Zhejiang University, Hangzhou, Zhejiang, China.

c Liver Research Center, Rhode Island Hospital and The Warren Alpert Medical School of

*Correspondence to: Tunan Yu, M.D, PhD (3314006@zju.edu.cn) or Xiujun Cai, M.D., ELSA, FACS (srrsh_cxj@zju.edu.cn), Department of General Surgery, Sir Run Run Shaw Hospital, School of Medicine, Zhejiang University, Hangzhou, 310016, Zhejiang Province, China 


\section{Abstract}

Background: The Wnt signaling pathway, an evolutionarily conserved molecular transduction cascade, has been identified to play a pivotal role in various physiological and pathological processes of the liver, including homeostasis, regeneration, cirrhosis, and hepatocellular carcinoma. In this study, we aimed to use a bibliometric method to evaluate the current status and emerging trends on Wnt signaling in liver diseases.

Methods: Articles were retrieved from the Web of Science Core Collection (WoSCC). We used a bibliometric software, CiteSpace V 5.3.R4, to analyze the active countries or institutions in the research field, the landmark manuscripts, research subtopics, and evolution of scientific ideas.

Results: In total, 1,768 manuscripts were published, and each was cited 33.12 times on average. The U.S. published most of the manuscripts, and the most active center was the University of Pittsburgh. The top 5 landmark papers were identified by four bibliometric indexes including citation, burstness, centrality, and usage 2013. The clustering process divided the whole area into 9 research subtopics, and the two major subtopics were "liver zonation" and "hepatocellular carcinoma." Using the "Part-of-Speech" technique, 1,743 noun phrases were identified from the title/abstract of all manuscripts and references. After 2008, the bursting phrases were "liver development", "progenitor cells", "hepatic stellate cells", "liver regeneration", "liver fibrosis", "epithelial-mesenchymal transition" and etc.

Conclusion: Using bibliometric methods, we quantitatively summarized the advancements and emerging trends in Wnt signaling in liver diseases. These bibliometric findings may pioneer the future direction of this field in the next few years, and further studies are needed.

\section{Abbreviations}

WOSCC: Web of Science Core Collection; HCC: hepatocellular carcinoma; WOS: Web of Science; INSERM: Institut National de la Santé et de la Recherche Médicale; Fzd2: Frizzled2; 
The Wnt signaling pathway, an evolutionarily conserved molecular transduction cascade, has been identified to play a pivotal role in various diseases[1], including degenerative diseases [2, 3], chronic inflammation [4], and malignancy [5] (Figure 1). Dysregulation of the Wnt pathway is correlated with dysfunction in different organs including the teeth [6], eye [7], and heart [8]. In the liver, the Wnt pathway is essential for homeostasis, embryogenesis, development, maturation, and regeneration [9]. It is also associated with several pathological conditions such as cirrhosis [10], hepatoblastoma [11, 12], and hepatocellular carcinoma (HCC)[13]. Currently, several Wnt molecules with potential pharmacological value are being explored for future therapeutic interventions $[14,15]$.

Using of bibliometric methods is a novel way to summarize the advancements in a research area. Several bibliometric methods have been developed to construct knowledge maps, which can detect hotspots or even emerging trends in a research area. Several softwares are avaliable to conduct research for this aim, including CiteSpace [16], CitNetExplorer, Vosviewer [17], and HistCite [18]. Although most of the bibliometric studies are currently performed in the area of scientometrics or social science $[19,20]$, some researchers have made similar attempts in the field of biomedicine. For example, Shuaib et al investigated the top 100 papers in the area of cardiovascular research [21], and Zhou et al critically analyzed studies on liposomes from 1995 to 2014 [22]. In this study, we aimed to use bibliometric methods to analyze manuscripts on the Wnt signaling pathway in liver diseases. Using CiteSpace, we aimed to identify the active countries or institutions in the research field, the landmark manuscripts, research subtopics, and the evolution of scientific ideas.

\section{Methods}

The authors conducted a search of literature on the Web of Science Core Collection (WOSCC) on Nov 15th, 2018 to obtain articles on the Wnt signaling pathway in liver diseases. The key words "wnt" and "liver" were mainly utilized. According to Prof. Chaomei Chen [23], the inventor of CiteSpace, it is unnecessary to endlessly refine search queries to eliminate papers of irrelevant topics. Instead, CiteSpace could differentiate those papers during the process of clustering. Each manuscript was downloaded in the manner of "full records and cited 
references." The information on the titles, keywords, author, institution, country, abstract, and references was all stored.

The bibliometric software CiteSpace V 5.3.R (64 bits) [16] was utilized for this study. In a co-citation network for literature, every node represents a reference paper, and a link between two nodes represents the relation of citing. Co-citation maps could also be constructed for countries or institutions, and the links between two nodes represent co-operation between two countries or institutions. To simplify the structure of the co-citation network, a restriction with gindex [24] was utilized, and the scale factor $\mathrm{k}$ was set as 5. To evaluate the importance of a node in a network, four indexes, i.e. total citation number, betweenness centrality, burstness, and usage 2013 were utilized. Betweenness centrality [25] is defined as a metric of a node in a network that measures how likely an arbitrary shortest path in the network will go through the node. The concept of "centrality" arose from studies in the social network. A node with higher centrality is more likely to connect several areas, and even be a turning point in a science domain [26]. Burstness is defined as the count of citation for a node that is sharply increasing throughout time [27]. Usage 2013 is an index developed by the WOSCC and indicates the times of "usage" since the year 2013 by all Web of Science users, such as by clicking links to the full-length article or saving the article for use in a bibliographic management tool [28].

Several other bibliometric techniques were also utilized. Firstly, the process of "clustering" was used to identify different research subtopics in all the papers on "Wnt signaling in liver diseases." The quality of clustering was measured by two indexes, modularity and silhouette scores [29]. The label of each cluster was summarized from the title of the references, with the method of log-likelihood (LLR). Secondly, changes and evolution of scientific concepts over the years were evaluated. "Circles visulization" (Supplementary Figure 1) generated by Carrot 2 [31] was utilized to identify keywords of importance, and give relative impact to each keyword based on its calculated value Moreover, the "Part-of-Speech" technique [30] of CiteSpace was used to retrieve noun phrases from titles. The noun phrases could be considered as substitutions of scientific ideas, and were used to construct a co-citation network. For each noun phrase, the minimum number of words was two and the maximum number was four. The noun phrases with the highest burstness in the network were identified to represent the scientific ideas over the 
105

106

107

108

109

110

111

112

113

114

115

116

117

118

119

120

121

122

123

124

125

126

127

128

129

130

131

years.

6

\section{Results}

1. Publication outputs

Using the aforementioned search strategy, a total of 1,768 manuscripts were identified. On an average, each manuscript was cited 33.12 times. The number of manuscripts was increasing since the year 1994 (Figure 2). Among these manuscripts, there were 1,425 articles, 231 reviews, 82 meeting abstracts, 21 editorial materials, and 18 proceeding papers. Of these 1,753 manuscripts were written in English .

2. Country and institutional analysis

A total of 35 countries and areas had published manuscripts, and the top five countries were the U.S. (648), China (516), Germany (179), Japan (175), and France (124). Globally, a total of 1,887 institutions published manuscripts independently or co-operatively, and most of them were scattered in North America, East Asia, and Europe. The top 5 institutions were the University of Pittsburgh (99), Institut National de la Santé et de la Recherche Médicale (INSERM, 96), Université Paris Descartes (51), Shanghai Jiao Tong University (47), and Fudan University (43).

3. Landmark manuscripts

The whole science domain was constructed with 1,768 manuscripts combined with their 57,478 references. After simplifying the network with the g-index, the five most cited manuscripts were identified, as the studies by Satoh et al [32], Benhamouche et al [33], Thompson et al [34], and two studies by Clevers et al in 2006 [35] and 2012 [36](Figure 3). Further,-we selected the top 5 manuscripts by the indexes of betweenness citation, centrality, burstness, and usage 2013 (Table 1).

4. Research subtopics

In Figure 4, the whole co-citation map of manuscripts was divided into nine clusters as "liver zonation", "hepatocellular carcinoma", "human colorectal cancer", "liver tumor", "stem cell niche", "murine hepatic transit", "liver stem cell”, "alpha-wnt10b signaling loop" 
132

133

and "endothelial cell niche". The modularity for this clustering was 0.6406 , and the mean silhouette was 0.7945 . Among them, the two largest clusters were "liver zonation (0\#)"and "hepatocellular carcinoma (1\#). In the cluster of "liver zonation", three papers citing most of the members in this cluster were the works of Torre et al [51], Gebhardt et al [52], and Braeunning et al [53]. In the cluster of "hepatocellular carcinoma", three papers citing most of the members in this cluster were the studies by Nejak-Boweni et al [54], Monga et al [55], and Wei et al [56].

5. Evolution of scientific ideas

Circles visulization generated by Carrot 2 (Supplementary Figure 1) was generated to identify keywords in the whole science domain. Some keywords with research importance were identified, such as "Cancer genes", "Signaling in Hepatocytes", "Pathway Mutations", "Betacatenin in Mice", "Liver of Patients", and "Liver Stem". To a certain degree, these keywords could reflect current trends in the research area (Figure 5a).

Using the "Part-of-Speech" technique of CiteSpace, 1,743 noun phrases in the titles of manuscripts were detected by natural language analysis. A co-citation network of the noun phrases was constructed, and 43 of the phrases were found to have burstness (Supplementary Figure 2). Among them, 15 with scientific importance were specifically analyzed (Table 2). Before 2008, the keywords of scientific importance were "beta-catenin gene", "nuclear accumulation", "adenomatous polyposis coli", "genetic alterations", "beta-catenin mutations", "hepatocellular carcinomas", "wnt pathway" and "liver development". While after 2008, the bursting phrases were "liver development", "progenitor cells", "hepatic stellate cells", "liver regeneration", "liver fibrosis" and "epithelial-mesenchymal transition". The bursting phrases after 2008 had the potential to be future hotspots (Figure 5b).

\section{Discussion}

In the field of Wnt signaling in liver diseases, the number of manuscripts is increasing annually. Before 2015, the number of studies was even increasing exponentially. After 2016, the annual number of studies was about 180 to 200 . The whole scientific area constituted of 1,768 
160 records, 57,478 references and much a higher number of relations of citing or being cited.

161 Therefore, although several reviews based on expert opinions have already been published, bibliometric analysis using artificial intelligence algorithms is still needed to provide a bird-view of the whole area, which could also help analyze current trends and predict hotspots in the future.

CiteSpace, a high-quality bibliometric software, was used for most of the analyses in this study, and most of its functions were utilized. For instance, to simplify a complex co-citation network of literatures, g-index was used as a rule for restriction. However, CiteSpace could also use other restrictions such as the top 50 papers per slice, top $10 \%$ per slice, or adjusting the time interval per slice as two years [23]. To measure the importance of each node, four bibliometric indexes were utilized, including total number of citations in co-citation network, centrality, burstness, and usage 2013. The last three indicators were seldom utilized in non-bibliometric publications.

Using these indexes, several landmark manuscripts were identified. For example, the work of He TC et al [38] was included among the top 5 in centrality and the top 5 in burstness. This manuscript answered a question about the Wnt signaling pathway in the process of carcinogenesis: "How a Growth Control Path Takes a Wrong Turn to Cancer"[71]. This paper was cited by a large number of papers on Wnt signaling in hepatocellular carcinoma, such as the studies by Van Nhieu et al [57] and Merle et al [72]. The work by Satoh et al [32] was among the top 5 in citation as well as the top 5 in burstness. It suggested that Axin 1 might be a molecular target suppressing the growth of hepatocellular carcinoma. Furthermore, the index of usage 2013 identified manuscripts that were highly valued during these five years. For example, the study by Mokkapati et al [47] in 2014 suggested that Wnt pathway activation was sufficient for malignant transformation of a type of liver progenitor cells.

By the process of clustering in CiteSpace, the whole science domain was divided into nine subtopics. The largest two clusters are "liver zonation "and "hepatocellular carcinoma." "Liver zonation" meant that hepatocytes in different zones of the liver were heterogeneous in biochemical and physiological functions. This difference was also known as metabolic zonation. The Wnt signaling cascade played a dominant role in governing metabolic zonation [73], especially in the pathways of glutamine synthesis [74] and drug metabolism [75]. Some papers also highly cited the references in this cluster. For example, one was the review by Gebhardt et al 
190 [52], which proposed a three-level model for the molecular interpretation of beta-catenin activity

191 in metabolic zonation. In the field of "hepatocellular carcinoma," dysfunction in Wnt signaling

192

193

194

195

196

197

198

199 was considered to reactivate some molecular cascades in embryogenesis and induce the transformation of normal hepatocytes to the malignant phenotype [13]. Certain molecules in the Wnt pathway, including the extracellular, cytosolic, and nuclear participants, were explored to determine whether they were potential targets for therapeutic interventions [76]. The liver stem cell pathway was also mentioned in cluster "stem cell niche" and "liver stem cell". Wnt signaling is essential in stem cell control, as a proliferative and self-renewal signal. Several highquality reviews have analyzed this topic $[77,78]$. Finally, it was noteworthy to find that cluster "human colorectal cancer" was not directly related to liver research. However, since some important Wnt molecules were firstly investigated in the study of colon cancer, references of this subtopic were also highly cited by studies focusing on liver research.

Bibliometric methods can quantitatively identify some active words in research, and then judge the emerging trends and future prospects in a science domain. These noun phrases could also be directly derived from author keywords or the "key words plus" generated by WOS. However, in this study, we used an artificial intelligence-based "Part-of-Speech" technique to generate noun phrases directly from the titles/abstract, and then constructed a co-citation network of scientific ideas with more importance. This novel strategy was not feasible with traditional reviews. Through this strategy, we found some important phrases after 2008. For example, the phrase "liver fibrosis" had its bursting period during 2015 and 2016. One study using this phrase was the review by Miao et al [69], in which Wnt signaling was summarized to promote liver fibrosis by enhancing hepatic stellate cell activation and survival. The phrase "epithelialmesenchymal transition" had its bursting period during 2016 and 2018. The study by Gujral et al [70] investigated the Wnt receptor Frizzled2 (Fzd2) in epithelial-mesenchymal transition, and suggested that using an antibody to Fzd2 was a novel way to inhibit tumor growth and metastasis. Together with the results from Carrot 2 and "Part-of-Speech" analysis, understanding of current trends and future prospects were interpreted in Figure 5 based on bibliometric analysis.

This study had several limitations. One was that the co-citation analysis of manuscripts was only feasible in papers derived from the WOSCC. Therefore, searching results from other 
220 databases including PubMed, Ovid, Scopus, and Google Scholar was not feasible using

221 CiteSpace. Secondly, this analysis did not show clusters about Wnt signaling in alcoholic liver

222 diseases or nonalcoholic steatohepatitis. Although there were several studies on Wnt signaling in

223 these diseases [79, 80], the number of studies highly cited was not enough. Therefore, the

224 simplified co-citation map did show these papers as important nodes.

225 In conclusion, using the bibliometric methods, we quantitatively summarized the

226 advancements and emerging trends in Wnt signaling in liver diseases. These bibliometric

227 findings may pioneer the future direction of this field in the next few years, and further studies

228 are needed.

\section{Acknowledgment}

231

232

233

234

235

236

237

238

239

240

\section{Reference}

242

243
Not applicable

1. Nusse R, Clevers H. Wnt/beta-Catenin Signaling, Disease, and Emerging Therapeutic Modalities. Cell. 2017;169(6):985-99. 
244 2. Gong Y, Slee RB, Fukai N, Rawadi G, Roman-Roman S, Reginato AM, Wang H, Cundy T, 245 Glorieux FH, Lev D, Zacharin M, Oexle K, Marcelino J, Suwairi W, Heeger S, Sabatakos G, Apte 246 S, Adkins WN, Allgrove J, Arslan-Kirchner M, Batch JA, Beighton P, Black GCM, Boles RG, Boon 247 LM, Borrone C, Brunner HG, Carle GF, Dallapiccola B, De Paepe A, Floege B, Halfhide ML, Hall B, 248 Hennekam RC, Hirose T, Jans A, Jüppner H, Kim CA, Keppler-Noreuil K, Kohlschuetter A, LaCombe D, Lambert M, Lemyre E, Letteboer T, Peltonen L, Ramesar RS, Romanengo M, Somer $H$, Steichen-Gersdorf E, Steinmann B, Sullivan B, Superti-Furga A, Swoboda W, van den Boogaard M-J, Van Hul W, Vikkula M, Votruba M, Zabel B, Garcia T, Baron R, Olsen BR, Warman ML. LDL Receptor-Related Protein 5 (LRP5) Affects Bone Accrual and Eye Development. Cell. 2001;107(4):513-23.

3. Cisternas P, Zolezzi JM, Martinez M, Torres VI, Wong GW, Inestrosa NC. Wnt-induced activation of glucose metabolism mediates the in vivo neuroprotective roles of Wnt signaling in Alzheimer disease. 2018.

4. Nalesso G, Thomas BL, Sherwood JC, Yu J, Addimanda O, Eldridge SE, Thorup AS, Dale L, Schett G, Zwerina J, Eltawil N, Pitzalis C, Dell'Accio F. WNT16 antagonises excessive canonical WNT activation and protects cartilage in osteoarthritis. Annals of the rheumatic diseases. 2017;76(1):218-26.

5. Anastas JN, Moon RT. WNT signalling pathways as therapeutic targets in cancer. Nature Reviews Cancer. 2013;13(1):11-26.

6. Yamashiro T, Zheng L, Shitaku Y, Saito M, Tsubakimoto T, Takada K, Takano-Yamamoto T, Thesleff I. Wnt10a regulates dentin sialophosphoprotein mRNA expression and possibly links odontoblast differentiation and tooth morphogenesis. Differentiation. 2010;75(5):452-62.

7. Cavodeassi F, Carreira-Barbosa F, Young RM, Concha ML, Allende ML, Houart C, Tada M, Wilson SW. Early stages of zebrafish eye formation require the coordinated activity of Wnt11, Fz5, and the Wnt/beta-catenin pathway. Neuron. 2005;47(1):43-56.

8. Todd H, Min Z, Jun W, Margarita BC, Ela K, Johnson RL, Martin JF. Hippo pathway inhibits Wnt signaling to restrain cardiomyocyte proliferation and heart size. Science. 2011;332(6028):458-61.

9. Perugorria MJ, Olaizola P, Labiano I, Esparza-Baquer A, Marzioni M, Marin JJG, Bujanda L, Banales JM. Wnt-beta-catenin signalling in liver development, health and disease. Nature reviews Gastroenterology \& hepatology. 2018.

10. Nishikawa K, Osawa Y, Kimura K. Wnt/beta-Catenin Signaling as a Potential Target for the Treatment of Liver Cirrhosis Using Antifibrotic Drugs. 2018;19(10).

11. Czauderna P, Garnier H. Hepatoblastoma: current understanding, recent advances, and controversies. F1000Research. 2018;7:53.

12. Bell D, Ranganathan S, Tao J, Monga SP. Novel Advances in Understanding of Molecular Pathogenesis of Hepatoblastoma: A Wnt/beta-Catenin Perspective. Gene expression. 2017;17(2):141-54.

13. Wands JR, Kim M. WNT/beta-catenin signaling and hepatocellular carcinoma. Hepatology. 2014;60(2):452-4.

14. Michael K. Can we safely target the WNT pathway? Nature Reviews Drug Discovery. 2014;13(7):513-32.

15. Pez F, Lopez A, Kim M, Wands JR, Caron de Fromentel C, Merle P. Wnt signaling and hepatocarcinogenesis: molecular targets for the development of innovative anticancer drugs. J Hepatol. 2013;59(5):1107-17.

16. Synnestvedt MB, Chen C, Holmes JH. CiteSpace II: visualization and knowledge discovery in bibliographic databases. AMIA Annual Symposium proceedings AMIA Symposium. 2005:724-8. 
291 17. van Eck NJ, Waltman L. Citation-based clustering of publications using CitNetExplorer and 292 VOSviewer. Scientometrics. 2017;111(2):1053-70.

293 18. Garfield E. Historiographic Mapping of Knowledge Domains Literature. Journal of 294 Information Science. 2004;30(2):119-45.

295 19. Jia LH. Mapping Knowledge Domain for the 2016 Nobel Prize in Economics: An Cite SpaceII Scientometrics Study Based on SSCI Da-tabase( 1990-2016). Journal of South China Normal University. 2017.

298 20. Liu G. Visualization of patents and papers in terahertz technology: a comparative study.

21. Shuaib W, Khan MS, Shahid H, Valdes EA, Alweis R. Bibliometric Analysis of the Top 100 Cited Cardiovascular Articles. The American Journal of Cardiology. 2015;115(7):972-81.

22. Zhou X, Zhao G. Global liposome research in the period of 1995-2014: a bibliometric analysis. Scientometrics. 2015;105(1):231-48.

23. Chen C. http://leanpub.com/howtousecitespace.

24. Egghe L. Theory and practise of the g-index. Scientometrics. 2006;69(1):131-52.

25. Chen C. The centrality of pivotal points in the evolution of scientific networks. 2005.

26. Chen C. Searching for intellectual turning points: Progressive knowledge domain visualization. Proc. Natl. Acad. Sei. USA, 101(suppl), 5303-5310. Proceedings of the National Academy of Sciences. 2004;101(suppl):5303-10.

27. Kleinberg J. Bursty and Hierarchical Structure in Streams. Data Mining \& Knowledge Discovery. 2003;7(4):373-97.

28. Wang X, Fang Z, Sun X. Usage patterns of scholarly articles on Web of Science: a study on Web of Science usage count. Scientometrics. 2016;109(2):917-26.

29. Chen C, Paul RJ, apos, Keefe B, O'Keefe B. Fitting the jigsaw of citation: Information visualization in domain analysis. Journal of the American Society for Information Science \& Technology. 2010;52(4):315-30.

30. https://nlp.stanford.edu/software/.

31. Osiński S, Weiss D, editors. Carrot2: Design of a Flexible and Efficient Web Information Retrieval Framework2005; Berlin, Heidelberg: Springer Berlin Heidelberg.

32. Satoh S, ., Daigo Y, ., Furukawa Y, ., Kato T, ., Miwa N, ., Nishiwaki T, ., Kawasoe T, ., Ishiguro $\mathrm{H}$, ., Fujita M, ., Tokino T, . AXIN1 mutations in hepatocellular carcinomas, and growth suppression in cancer cells by virus-mediated transfer of AXIN1. Nature Genetics. 2000;24(3):245.

33. Benhamouche S, Decaens T, Godard C, Chambrey R, Rickman DS, Moinard C, VasseurCognet M, Kuo CJ, Kahn A, Perret C. Tumor Suppressor Gene Is the "Zonation-Keeper" of Mouse Liver. Developmental Cell. 2006;10(6):759-70.

34. Thompson MD, Monga SP. WNT/beta-catenin signaling in liver health and disease. Hepatology. 2010;45(5):1298-305.

35. Clevers H. Wnt/beta-catenin signaling in development and disease. Cell. 2006;127(3):46980.

36. Clevers $H$, Nusse R. Wnt/ $\beta$-catenin signaling and disease. Cell. 2012;149(6):1192-205.

37. Alix de La Coste $B$, eacute. Somatic mutations of the $\beta$-catenin gene are frequent in mouse and human hepatocellular carcinomas. Proceedings of the National Academy of Sciences of the United States of America. 1998;95(15):8847-51.

38. T C H, A B S, C R, H H, L Z, L T dC, P J M, B V, K W K. Identification of C-MYC as a target of the APC pathway. Science. 1998;281(5382):1509.

39. O T, F M. Beta-Catenin regulates expression of cyclin D1 in colon carcinoma cells. Nature. 1999;398(6726):422-6. 
339 40. Ken T, Lewis R R, Ileana N A, Xiangyang D, Chiping Q, Linda M M, David M N, Lawrence J

340 B, Patrick C R, David I S. Mutational spectrum of beta-catenin, AXIN1, and AXIN2 in

341 hepatocellular carcinomas and hepatoblastomas. Oncogene. 2002;21(31):4863-71.

342 41. Benhamouche S, Decaens T, Godard C, Chambrey R, Rickman DS, Moinard C, Vasseur-

343 Cognet $\mathrm{M}$, Kuo CJ, Kahn A, Perret C, Colnot S. Apc tumor suppressor gene is the "zonation-

344 keeper" of mouse liver. Dev Cell. 2006;10(6):759-70.

345 42. Xinping T, Jaideep B, Benjamin C, George K M, Satdarshan P S M. Conditional deletion of beta-catenin reveals its role in liver growth and regeneration. Gastroenterology. 2006;131(5):1561-72.

348 43. Sandrine B, Rickman DS, Aurélien DR, Charles B, Sandra R, Emmanuelle J, Aurélie H, Jean $S$, Jacques $B$, Dominique $F$. Transcriptome classification of $\mathrm{HCC}$ is related to gene alterations and to new therapeutic targets. Hepatology. 2010;45(1):42-52.

44. Cécile G, Giuliana A, Sandrine I, Yannick L, Laura P, Ichrafe Ben M, Julien C, Paulette B-S, Mélanie L, Fran?oise D. Integrated analysis of somatic mutations and focal copy-number changes identifies key genes and pathways in hepatocellular carcinoma. Nature Genetics. 2012;44(6):694-8.

45. Li VW, Ng SS, Boersema P, Low T, Karthaus W, Gerlach J, Mohammed S, Heck AR, Maurice $M$, Mahmoudi T. Wnt Signaling through Inhibition of $\beta$-Catenin Degradation in an Intact Axin1 Complex. Cell. 2012;149(6):1245-56.

46. Kordes C, Häussinger D. Hepatic stem cell niches. Journal of Clinical Investigation. 2013;123(5):1874-80.

47. Mokkapati S, Niopek K, Huang L, Cunniff KJ, Ruteshouser EC, deCaestecker M, Finegold MJ, Huff $\mathrm{V}$. beta-catenin activation in a novel liver progenitor cell type is sufficient to cause hepatocellular carcinoma and hepatoblastoma. Cancer Res. 2014;74(16):4515-25.

48. Oishi N, Yamashita T, Kaneko S. Molecular biology of liver cancer stem cells. Liver cancer. 2014;3(2):71-84.

49. Sun G, Irvine KD. Control of growth during regeneration. Current topics in developmental biology. 2014;108:95-120.

50. Jors S, Jeliazkova P, Ringelhan M, Thalhammer J, Durl S, Ferrer J, Sander M, Heikenwalder M, Schmid RM, Siveke JT, Geisler F. Lineage fate of ductular reactions in liver injury and carcinogenesis. The Journal of clinical investigation. 2015;125(6):2445-57.

51. Torre C, Perret C, Colnot S. Molecular determinants of liver zonation. Progress in molecular biology and translational science. 97: Elsevier; 2010. p. 127-50.

52. Gebhardt R, Hovhannisyan A. Organ patterning in the adult stage: The role of $W n t / \beta$-catenin signaling in liver zonation and beyond. Developmental dynamics: an official publication of the American Association of Anatomists. 2010;239(1):45-55.

53. Braeuning A, Singh Y, Rignall B, Buchmann A, Hammad S, Othman A, von Recklinghausen I, Godoy P, Hoehme S, Drasdo D. Phenotype and growth behavior of residual $\beta$-catenin-positive hepatocytes in livers of $\beta$-catenin-deficient mice. Histochemistry and cell biology. 2010;134(5):469-81.

54. Nejak-Bowen KN, Monga SP, editors. Beta-catenin signaling, liver regeneration and hepatocellular cancer: sorting the good from the bad. Seminars in cancer biology; 2011: Elsevier.

55. Monga SPS. Role of Wnt/ $\beta$-catenin signaling in liver metabolism and cancer. The international journal of biochemistry \& cell biology. 2011;43(7):1021-9.

56. Wei Y, Fabre M, Branchereau S, Gauthier F, Perilongo G, Buendia M-A. Activation of $\beta$ catenin in epithelial and mesenchymal hepatoblastomas. Oncogene. 2000;19(4):498. 
57. Van Nhieu JT, Renard CA, Wei Y, Cherqui D, Zafrani ES, Buendia MA. Nuclear accumulation of mutated $\beta$-catenin in hepatocellular carcinoma is associated with increased cell proliferation. The American journal of pathology. 1999;155(3):703-10. 58. Valvezan AJ, Huang J, Lengner $\mathrm{CJ}$, Pack M, Klein PS. Oncogenic mutations in adenomatous polyposis coli (Apc) activate mechanistic target of rapamycin complex 1 (mTORC1) in mice and zebrafish. Disease models \& mechanisms. 2014;7(1):63-71.

59. Wei $Y$, Van Nhieu JT, Prigent S, Srivatanakul P, Tiollais P, Buendia MA. Altered expression of E-cadherin in hepatocellular carcinoma: Correlations with genetic alterations, $\beta$-catenin expression, and clinical features. Hepatology. 2002;36(3):692-701. 60. Chen YW, Jeng YM, Yeh SH, Chen PJ. p53 gene and Wnt signaling in benign neoplasms: $\beta$-catenin mutations in hepatic adenoma but not in focal nodular hyperplasia. Hepatology. 2002;36(4):927-35.

61. Capurro MI, Xiang Y-Y, Lobe C, Filmus J. Glypican-3 promotes the growth of hepatocellular carcinoma by stimulating canonical Wnt signaling. Cancer research. 2005;65(14):6245-54. 62. Grigoryan T, Wend P, Klaus A, Birchmeier W. Deciphering the function of canonical Wnt signals in development and disease: conditional loss-and gain-of-function mutations of $\beta$ catenin in mice. Genes \& development. 2008;22(17):2308-41.

63. Goessling W, North TE, Lord AM, Ceol C, Lee S, Weidinger G, Bourque C, Strijbosch R, Haramis A-P, Puder M. APC mutant zebrafish uncover a changing temporal requirement for wnt signaling in liver development. Developmental biology. 2008;320(1):161-74.

64. Yamashita T, Ji J, Budhu A, Forgues M, Yang W, Wang HY, Jia H, Ye Q, Qin LX, Wauthier E. EpCAM-positive hepatocellular carcinoma cells are tumor-initiating cells with stem/progenitor cell features. Gastroenterology. 2009;136(3):1012-24. e4.

65. Haughton EL, Tucker SJ, Marek CJ, Durward E, Leel V, Bascal Z, Monaghan T, Koruth M, Collie-Duguid E, Mann DA. Pregnane $X$ receptor activators inhibit human hepatic stellate cell transdifferentiation in vitro. Gastroenterology. 2006;131(1):194-209.

66. Llovet JM, Bruix J. Molecular targeted therapies in hepatocellular carcinoma. Hepatology. 2008;48(4):1312-27.

67. Itatsu K, Zen Y, Ohira S, Ishikawa A, Sato Y, Harada K, Ikeda H, Sasaki M, Nimura Y, Nakanuma $Y$. Immunohistochemical analysis of the progression of flat and papillary preneoplastic lesions in intrahepatic cholangiocarcinogenesis in hepatolithiasis. Liver International. 2007;27(9):1174-84.

68. Apte U, Singh S, Zeng G, Cieply B, Virji MA, Wu T, Monga SP. Beta-catenin activation promotes liver regeneration after acetaminophen-induced injury. The American journal of pathology. 2009;175(3):1056-65.

69. Miao C-g, Yang Y-y, He X, Huang C, Huang Y, Zhang L, Lv X-W, Jin Y, Li J. Wnt signaling in liver fibrosis: progress, challenges and potential directions. Biochimie. 2013;95(12):2326-35. 70. Gujral TS, Chan M, Peshkin L, Sorger PK, Kirschner MW, MacBeath G. A noncanonical Frizzled2 pathway regulates epithelial-mesenchymal transition and metastasis. Cell. 2014;159(4):844-56.

71. Pennisi E. How a growth control path takes a wrong turn to cancer. Science. 1998;281(5382):1438-9, 41.

72. Merle P, de la Monte S, Kim M, Herrmann M, Tanaka S, Von Dem Bussche A, Kew MC, Trepo C, Wands JR. Functional consequences of frizzled-7 receptor overexpression in human hepatocellular carcinoma. Gastroenterology. 2004;127(4):1110-22.

73. Rolf, Gebhardt, Madlen, Matz-Soja. Liver zonation: Novel aspects of its regulation and its impact on homeostasis. World Journal of Gastroenterology. 2014;20(26):8491-504. 
433 74. Shigeki S, Billy Yu-Ang L, Melanie B, Sandy F, Matthias H. Liver-specific loss of beta-catenin 434 blocks glutamine synthesis pathway activity and cytochrome p450 expression in mice.

435 Hepatology. 2010;43(4):817-25.

436 75. Zoé D B, Karen R R, Toby J P, Owen J S, Alan R C, David T. Liver zonation occurs through a 437 beta-catenin-dependent, c-Myc-independent mechanism. Gastroenterology. 2009;136(7):2316438 24.e3.

439 76. Floriane P, Ana?S L, Miran K, Wands JR, Claude CDF, Philippe M. Wnt signaling and 440 hepatocarcinogenesis: molecular targets for the development of innovative anticancer drugs. 441 Journal of Hepatology. 2013;59(5):1107-17.

442 77. Hans C, Kyle M L, Roel N. Stem cell signaling. An integral program for tissue renewal and 443 regeneration: Wnt signaling and stem cell control. Science. 2014;346(6205):1248012.

444 78. Reya T, Clevers H. Wnt signalling in stem cells and cancer. Nature. 2005;434:843. 445 79. Huang CK, Yu T, de la Monte SM, Wands JR, Derdak Z, Kim M. Restoration of Wnt/beta446 catenin signaling attenuates alcoholic liver disease progression in a rat model. J Hepatol. 447 2015;63(1):191-8.

448 80. Teratani T, Tomita K, Suzuki T, Furuhashi H, Irie R, Nishikawa M, Yamamoto J, Hibi T, 449 Miura S, Minamino T, Oike Y, Hokari R, Kanai T. Aortic carboxypeptidase-like protein, a WNT 450 ligand, exacerbates nonalcoholic steatohepatitis. The Journal of clinical investigation.

$451 \quad 2018 ; 128(4): 1581-96$.

452 
Figure 1

Signaling pathway for Wnt molecules (Depict by using Portable Pathway Builder 2.0 from ProteinLoung)

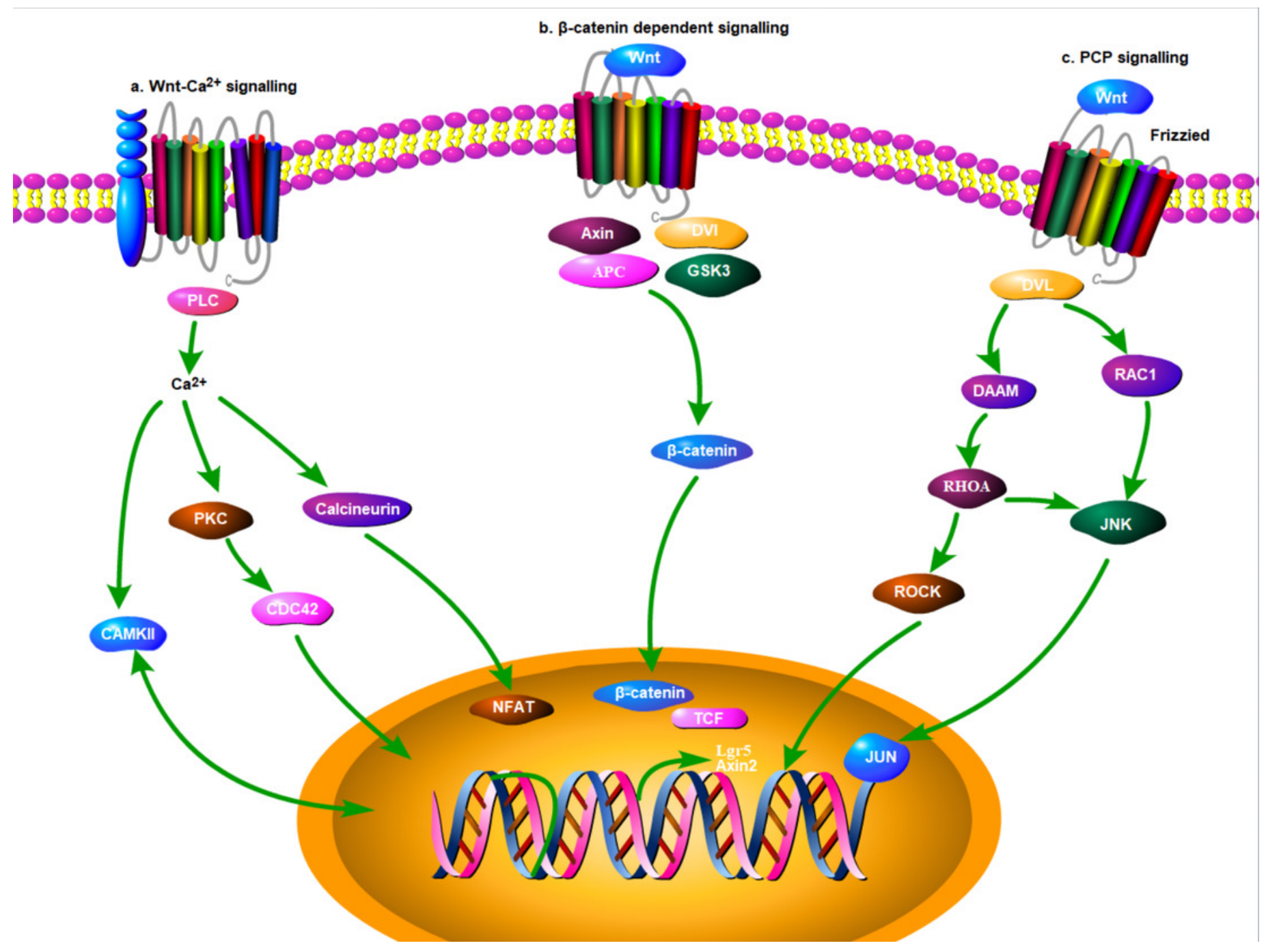


Figure 2

Annual publication about the Wnt signaling pathway in liver diseases

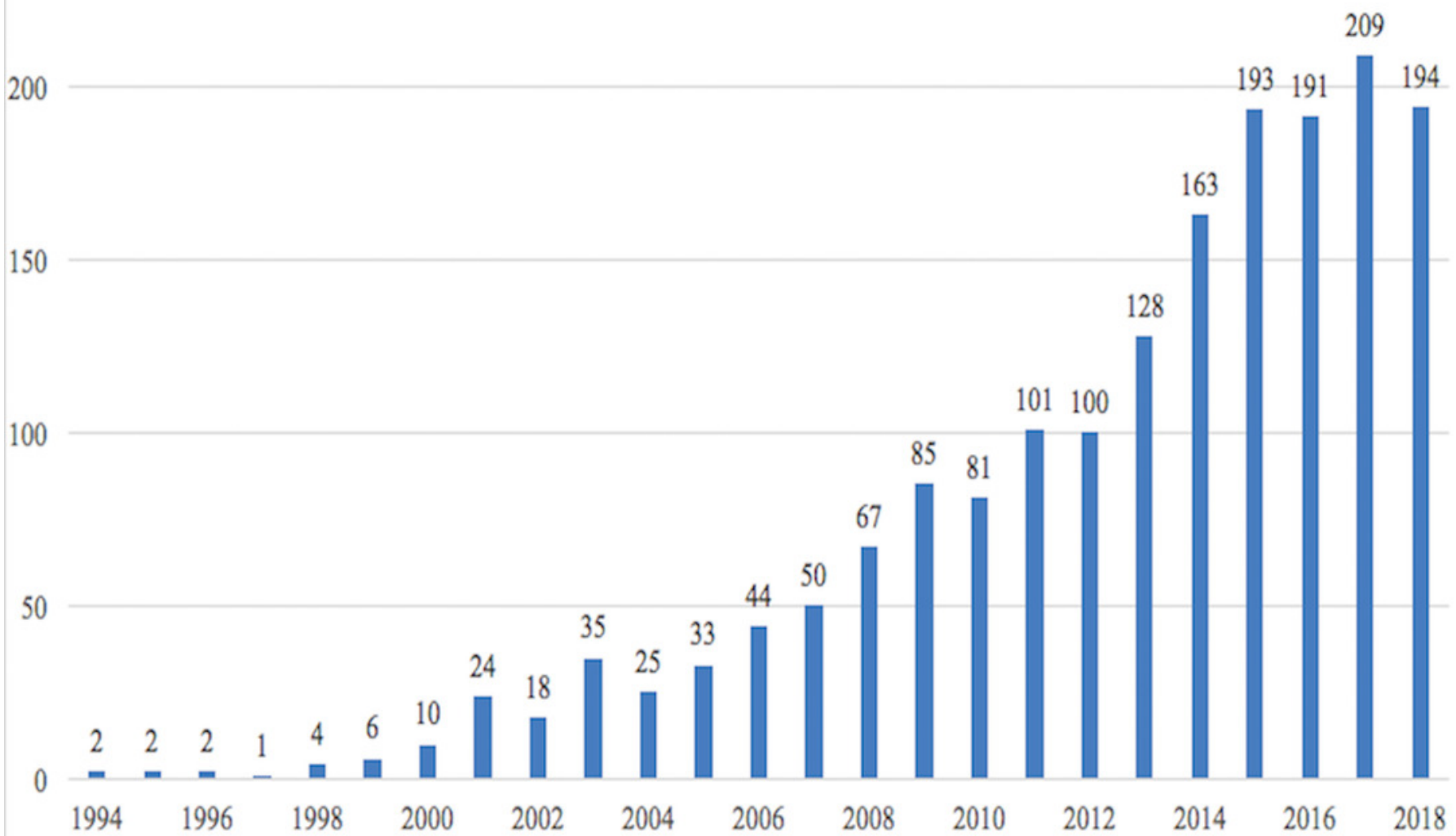


Figure 3

Top 5 manuscripts with highest co-citation in network

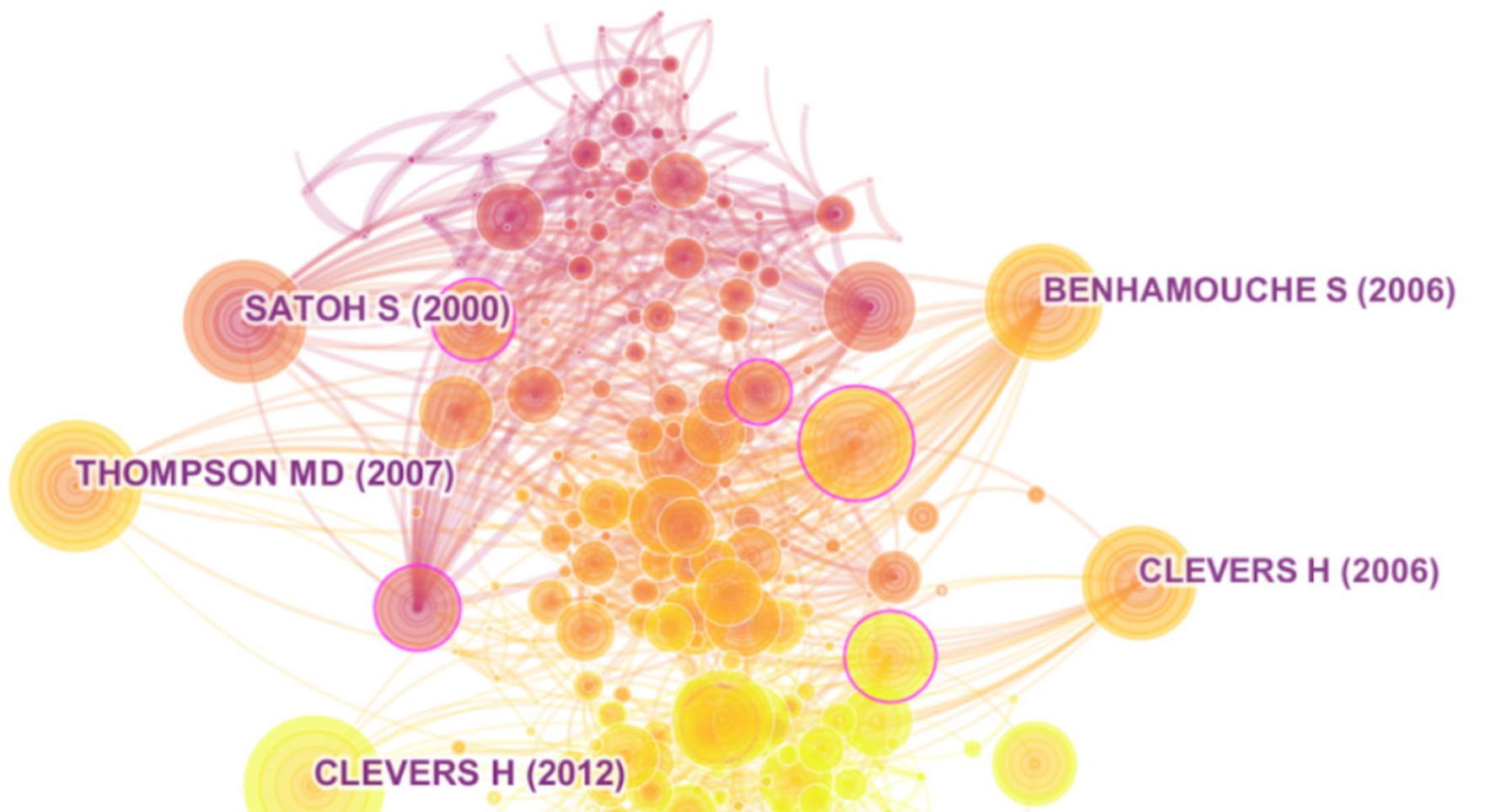


Figure 4

Two major subtopics, "liver zonation" and "hepatocellular carcinoma" identified during clustering 


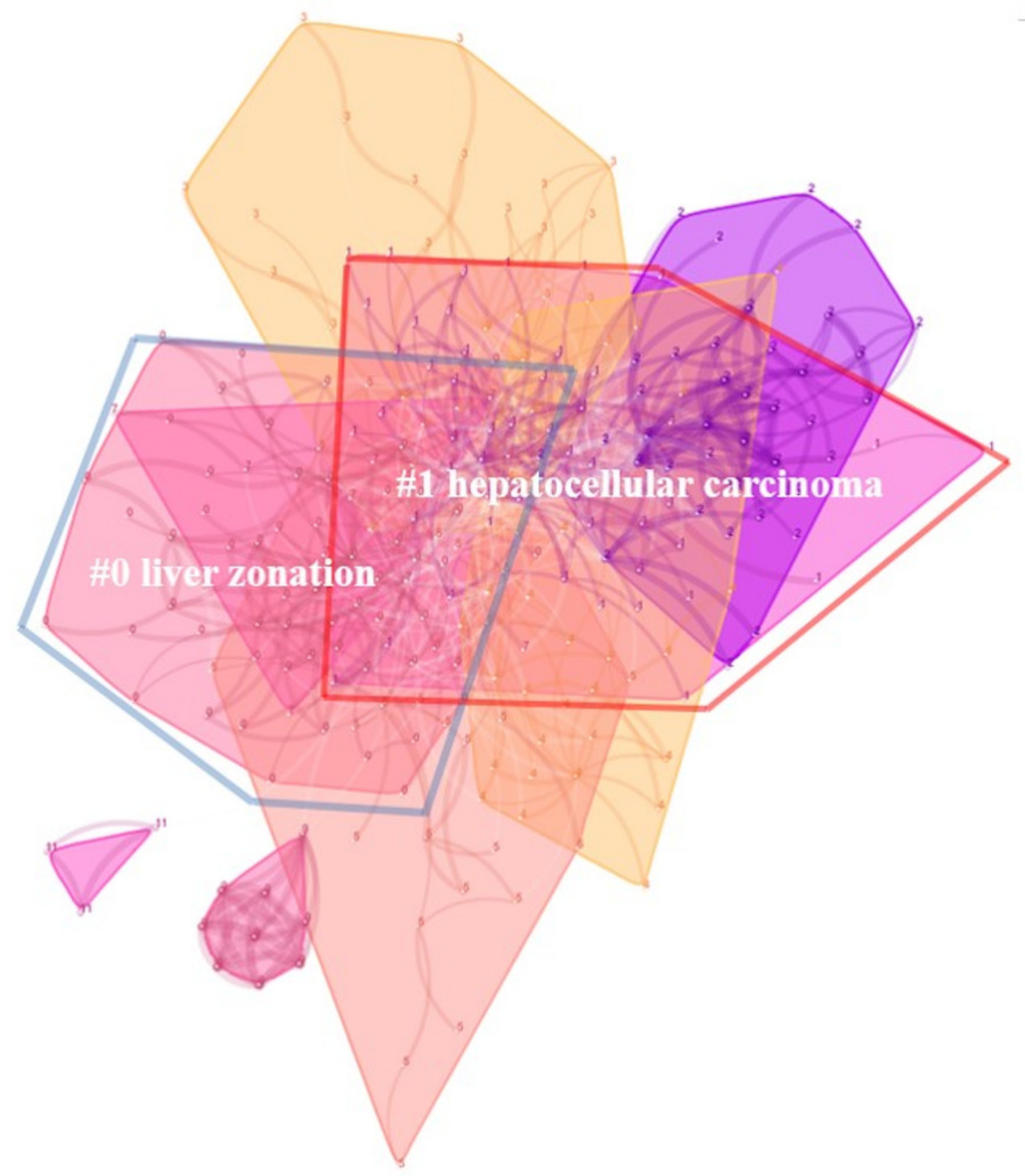




\section{Figure 5}

\section{Understanding of current trends and future prospect bases on bibliometric analyses}

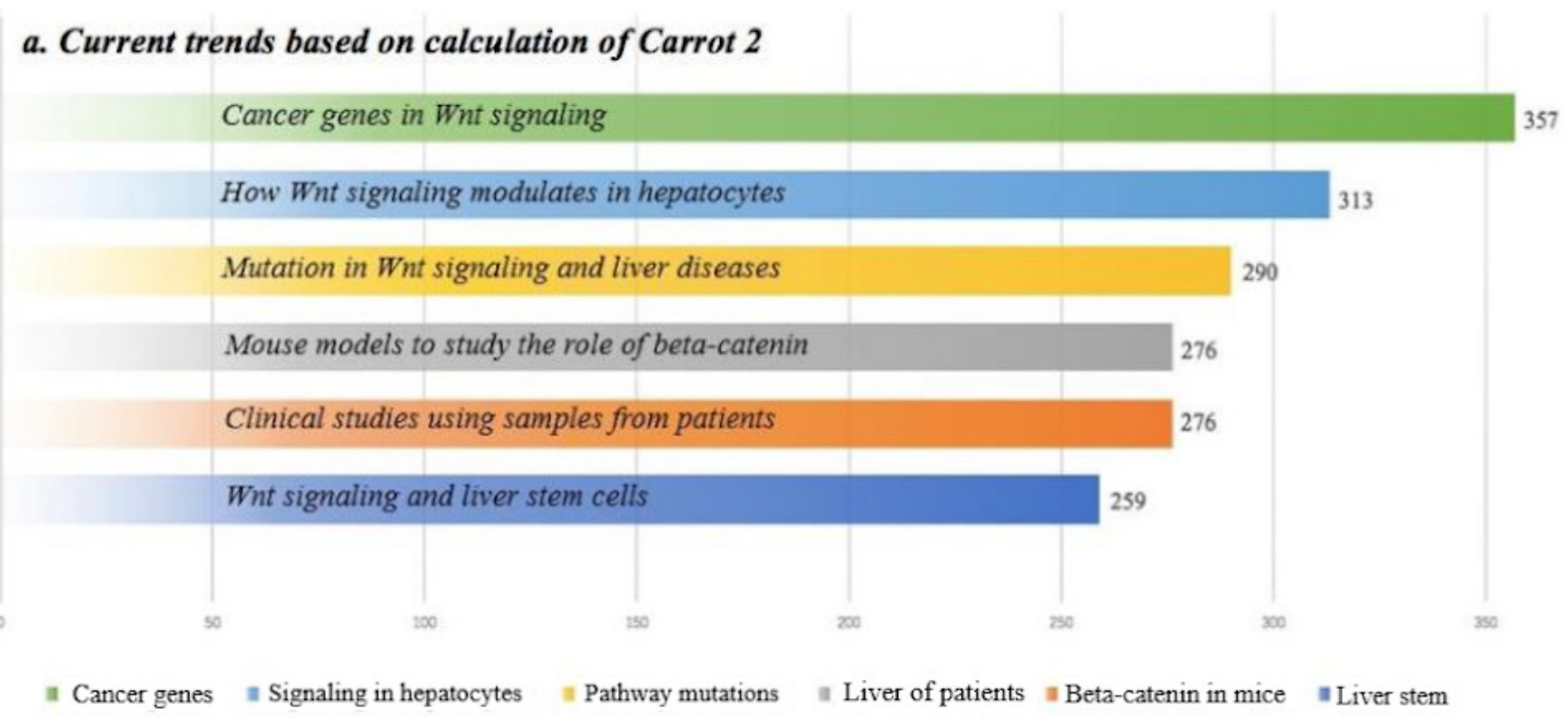

\section{b. Future prospect based on keywords with high burstness}

How Wnt signaling modulates liver development

Wnt signaling in liver progenitor/stem cells

1.9561 Role of Wnt signaling in hepatic stellate cells

0.538

Role of Wnt signaling in liver regeneration

Role of Wnt signaling in liver fibrosis

Wnt signaling and epithelial-mesenchymal transition

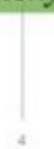

" Liver development " Progenitor cells " Hepatic stellate cells 


\section{Table 1 (on next page)}

Summarization of top 5 studies by the index of citation, centrality, burstness and usage 2013 


\begin{tabular}{|c|c|c|c|c|c|c|}
\hline Year & First author & Journal & Title & Top 5 & Top 5 & Top 5 \\
\hline 1998 & de La Coste A & PNAS & $\begin{array}{l}\text { Somatic mutations of the } \beta \text {-catenin gene are frequent in mouse and human hepatocellular } \\
\text { carcinomas[37] }\end{array}$ & & & $\mathrm{Y}$ \\
\hline 1998 & He T C & Science & Identification of c-MYC as a target of the APC pathway[38] & & $\mathrm{Y}$ & $\mathrm{Y}$ \\
\hline 1999 & Tetsu O & Nature & $\beta$-Catenin regulates expression of cyclin D1 in colon carcinoma cells[39] & & & $\mathrm{Y}$ \\
\hline 2000 & Satoh S & Nature genetics & $\begin{array}{l}\text { AXIN1 mutations in hepatocellular carcinomas, and growth suppression in cancer cells by virus- } \\
\text { mediated transfer of AXIN1[32] }\end{array}$ & $\mathrm{Y}$ & & $\mathrm{Y}$ \\
\hline 2006 & Clevers $\mathrm{H}$ & Cell & Wnt $/ \beta$-catenin signaling in development and disease[35] & $\mathrm{Y}$ & & \\
\hline 2002 & Taniguchi K & Oncogene & $\begin{array}{l}\text { Mutational spectrum of } \beta \text {-catenin, AXIN1, and AXIN2 in hepatocellular carcinomas and } \\
\text { hepatoblastomas[40] }\end{array}$ & & $\mathrm{Y}$ & \\
\hline 2006 & Benhamouche S & Developmental cell & Apc tumor suppressor gene is the "zonation-keeper" of mouse liver[41] & $\mathrm{Y}$ & & \\
\hline 2006 & Tan X & Gastroenterology & Conditional deletion of $\beta$-catenin reveals its role in liver growth and regeneratio[42] & & $\mathrm{Y}$ & \\
\hline 2010 & Thompson M D & Hepatology & WNT $/ \beta$ - catenin signaling in liver health and disease $[34]$ & $\mathrm{Y}$ & & \\
\hline 2007 & Boyault S & Hepatology & $\begin{array}{l}\text { Transcriptome classification of HCC is related to gene alterations and to new therapeutic } \\
\text { targets[43] }\end{array}$ & & $\mathrm{Y}$ & \\
\hline 2012 & Guichard C & Nature genetics & $\begin{array}{l}\text { Integrated analysis of somatic mutations and focal copy-number changes identifies key genes and } \\
\text { pathways in hepatocellular carcinoma[44] }\end{array}$ & & $\mathrm{Y}$ & \\
\hline 2012 & Clevers $\mathrm{H}$ & Cell & Wnt $\beta$-catenin signaling and disease[36] & $\mathrm{Y}$ & & \\
\hline 2012 & LiVSW & Cell & Wnt signaling through inhibition of $\beta$-catenin degradation in an intact Axin1 complex [45] & & & $\mathrm{Y}$ \\
\hline 2013 & Kordes C & $\begin{array}{l}\text { The Journal of Clinical } \\
\text { Investigation }\end{array}$ & Hepatic stem cell niches[46] & & & \\
\hline 2014 & Mokkapati S & Cancer Research & $\begin{array}{l}\beta \text {-catenin activation in a novel liver progenitor cell type is sufficient to cause hepatocellular } \\
\text { carcinoma and hepatoblastoma [47] }\end{array}$ & & & \\
\hline 2014 & Oishi $N$ & Liver Cancer & Molecular Biology of Liver Cancer Stem Cells[48] & & & \\
\hline 2014 & Sun $\mathrm{G}$ & $\begin{array}{l}\text { Current Topics in } \\
\text { Developmental Biology }\end{array}$ & Control of growth during regeneration.[49] & & & \\
\hline 2015 & Jörs S & The Journal of Clinical & Lineage fate of ductular reactions in liver injury and carcinogenesis $[50]$ & & & \\
\hline & & Investigation & & & & \\
\hline
\end{tabular}


Table 2 (on next page)

Summarization of 15 noun phrases in citation network to have burstness 


\begin{tabular}{|c|c|c|c|c|c|}
\hline Term & Strength & Begi & End & Sample paper & Journal \\
\hline beta-catenin gene & 8.3092 & 1998 & 2005 & $\begin{array}{l}\text { Somatic mutations of the } \beta \text {-catenin gene are frequent in mouse and human hepatocellular } \\
\text { carcinomas }[37]\end{array}$ & Oncogene \\
\hline nuclear accumulation & 2.9721 & 2002 & 2005 & $\begin{array}{l}\text { Nuclear accumulation of mutated beta-catenin in hepatocellular carcinoma is associated with } \\
\text { increased cell proliferation[57] }\end{array}$ & $\begin{array}{l}\text { The American Journal of } \\
\text { Pathology }\end{array}$ \\
\hline adenomatous polyposis coli & 6.4555 & 2002 & 2006 & $\begin{array}{l}\text { Oncogenic mutations in adenomatous polyposis coli (Apc) activate mechanistic target of } \\
\text { rapamycin complex } 1 \text { (mTORC1) in mice and zebrafish [58] }\end{array}$ & $\begin{array}{l}\text { Disease models \& } \\
\text { mechanism }\end{array}$ \\
\hline genetic alterations & 3.7144 & 2002 & 2006 & $\begin{array}{l}\text { Altered expression of E-cadherin in hepatocellular carcinoma: Correlations with genetic } \\
\text { alterations, beta-catenin expression, and clinical features [59] }\end{array}$ & Hepatology \\
\hline beta-catenin mutations & 9.2414 & 2002 & 2005 & $\begin{array}{l}\text { P53 gene and wnt signaling in benign Neoplasms: beta-Catenin mutations in hepatic adenoma } \\
\text { but not in focal nodular hyperplasia [60] }\end{array}$ & Hepatology \\
\hline hepatocellular carcinomas & 8.0349 & 2007 & 2011 & $\begin{array}{l}\text { Glypican-3 promotes the growth of hepatocellular carcinoma by stimulating canonical Wnt } \\
\text { signaling [61] }\end{array}$ & Cancer research \\
\hline wnt pathway & 2.8812 & 2008 & 2011 & $\begin{array}{l}\text { Deciphering the function of canonical Wnt signals in development and disease: conditional } \\
\text { loss- and gain-of-function mutations of alpha-catenin in mice [62] }\end{array}$ & Genes \& development \\
\hline liver development & 6.2437 & 2008 & 2009 & $\begin{array}{l}\text { APC mutant zebrafish uncover a changing temporal requirement for wnt signaling in liver } \\
\text { development [63] }\end{array}$ & Developmental biology \\
\hline progenitor cells & 8.8815 & 2009 & 2010 & $\begin{array}{l}\text { EpCAM-Positive Hepatocellular Carcinoma Cells Are Tumor-Initiating Cells With } \\
\text { Stem/Progenitor Cell Features [64] }\end{array}$ & Gastroenterology \\
\hline hepatic stellate cells & 1.9561 & 2009 & 2010 & $\begin{array}{l}\text { Pregnane } \mathrm{X} \text { receptor activators inhibit human hepatic stellate cell transdifferentiation in vitro } \\
{[65]}\end{array}$ & Gastroenterology \\
\hline aberrant activation & 3.9739 & 2010 & 2011 & Molecular targeted therapies in hepatocellular carcinoma [66] & Hepatology \\
\hline cyclin $\mathrm{d} 1$ & 1.0341 & 2012 & 2013 & $\begin{array}{l}\text { Immunohistochemical analysis of the progression of flat and papillary preneoplastic lesions } \\
\text { in intrahepatic cholangiocarcinogenesis in hepatolithiasis [67] }\end{array}$ & Liver International \\
\hline liver regeneration & 0.538 & 2015 & 2016 & $\begin{array}{l}\text { Beta-Catenin Activation Promotes Liver Regeneration after Acetaminophen-Induced Injury } \\
{[68]}\end{array}$ & $\begin{array}{l}\text { The American journal of } \\
\text { pathology }\end{array}$ \\
\hline liver fibrosis & 6.8307 & 2015 & 2016 & Wnt signaling in liver fibrosis: Progress, challenges and potential directions [69] & Biochimie \\
\hline $\begin{array}{l}\text { epithelial-mesenchymal } \\
\text { transition }\end{array}$ & 6.939 & 2016 & 2018 & $\begin{array}{l}\text { Noncanonical Frizzled2 Pathway Regulates Epithelial-Mesenchymal Transition and } \\
\text { Metastasis [70] }\end{array}$ & Cell \\
\hline
\end{tabular}

